\title{
Diagnostic Dilemma of a Pelvic-Abdominal Mass in a Teenage Girl
}

\author{
A.S. Dhillon ${ }^{1}$, Kartika Pandey ${ }^{2}$ \\ 1, 2 Department of Obstetrics and Gynaecology, Maharishi Markandeshwar \\ Institute of Medical Sciences and Research, Mullana, Haryana, India.
}

\section{INTRODUCTION}

The differential diagnosis of an abdominal mass in young teenage girls include pelvic inflammatory disease, pelvic abdominal Koch's, endometriosis, pedunculated uterine leiomyomata, colonic mass, and germ cell tumour. There is a strong possibility of benign, borderline, or malignant ovarian carcinoma to be diagnosed in young girls with abdominal mass.

Preoperative diagnosis depends on age, menopausal status, serum cancer antigen (CA) level of 125, ultrasound and radiological imaging of the mass. For better diagnosis of benign borderline serous tumours, borderline ovarian tumours (BOTs) and invasive cancers, magnetic resonance imaging (MRI) and positron emission tomography has to be done. However, among patients with benign cysts, BOTs and invasive cancers, CA-125 levels can be same. Likewise, the imaging results are not unique to BOTs. The diagnosis of BOTs can therefore be not established before surgery and intraoperative decisions regarding the extent of surgical management are based on the results of frozen section examination.

In BOTs, an effective frozen section diagnosis is of considerable significance. Women of reproductive age always want traditional fertility-sparing surgery. Benign cysts should be distinguished from BOTs. Inadequate surgical staging of BOT may result in misdiagnosis of BOT as a benign tumour, leading to more vigorous treatment and possible tumour spread. ${ }^{1}$

\section{PRESENTATION OF CASE}

This 21-year-old unmarried female came to the outpatient department (OPD) with complaints of abdominal swelling which was gradually increasing in size, difficulty in micturition and constipation for $3-4$ years and weight loss since $3-4$ months that was associated with fever since 1 - 2 months. Her menstrual cycle was regular and not associated with dysmenorrhea (painful menstruation). She was a known case of pulmonary tuberculosis and received anti-tubercular treatment (ATT) in 2015, 2018 and 2019 based on chest x-ray findings. Currently, patient was on ATT. On examination, patient's general condition was good with pulse rate (PR) - 84 / min, blood pressure (BP) - $110 / 70 \mathrm{~mm} \mathrm{hg}$, temperature - 98.4, respiratory rate (RR) - 18 / min and oxygen saturation (SPO2) - $99 \%$ on room air. The general physical examination (GPE) and systemic examinations were normal. No significant lymphadenopathy was noted.

On posteroanterior (P / A) examination, abdominopelvic mass of $12 \mathrm{X} 10 \mathrm{~cm}$ was felt in the midline towards the left iliac fossa, The mass was smooth, firm, non-tender with irregular margins and restricted mobility. Flanks were not full. No shifting dullness or fluid thrill elicited. There was no bleeding or discharge per vagina.
Corresponding Author: Dr. Kartika Pandey, Room no 200, I block, MMU, Mullana, Ambala, Haryana - 133207, India. E-mail: kaarti_007@yahoo.com

DOI: $10.14260 / j e m d s / 2021 / 402$

How to Cite This Article:

Dhillon AS, Pandey K. Diagnostic dilemma of a pelvic - abdominal mass in a teenage girl. J Evolution Med Dent Sci 2021;10(26): 1957-1960, DOI:

10.14260/jemds/2021/402

Submission 13-12-2020,

Peer Review 28-04-2021,

Acceptance 05-05-2021,

Published 28-06-2021.

Copyright (c) 2021 A.S. Dhillon et al. This is an open access article distributed under Creative Commons Attribution License [Attribution 4.0 International (CC BY 4.0)] 
The provisional diagnosis of this large abdominopelvic mass was abdominal Koch's with differential diagnosis of ovarian malignancy was made based on the patient's clinical profile. Patient was admitted in MMIMSR and was further investigated.

Routine investigation, sputum examination for acid fast bacilli, tumour markers along with ultrasonography and MRI of whole abdomen + pelvis was done at MMIMSR on 27 / 7 / 2019 which showed large abdominopelvic mass suggestive of either a complicated endometrioma or mucinous tumour with pyosalpinx or haematosalpinx. MRI of whole abdomen and pelvis was again done on 26 / 7 / 2020, which showed large abdominopelvic cystic lesion appearing to arise from left side of pelvis extending to epigastrium, bilateral lumbar and iliac quadrants. Thus, it appeared to be originating from left adnexa and could be an ovarian surface epithelial tumour (serous). It measured $18 \mathrm{~cm}$ (CC) x $17 \mathrm{~cm}$ (TR) x $8.8 \mathrm{~cm}$ (AP). A small irregularly marginated solid non-mobile mass was cited at the floor of this lesion measuring $18 \times 14 \mathrm{~mm}$. This vascular, small solid component raised suspicion of malignancy. There were multiple right ovarian cysts noticed, some of which were haemorrhagic.

Uterus appeared normal. Myometrium was normal. Junctional zone was normal. No free fluid was seen in pelvis. Her $\mathrm{Hb}$ was 12.1, TLC was 7.5 and platelet was 1.91. Liver function test, renal function tests were within normal limits. Sputum for acid fast bacilli (AFB) was negative. Tumour markers: alpha fetoprotein was $0.7 \mathrm{ng} / \mathrm{ml}$, beta - HCG: 0.01 $\mathrm{mIU} / \mathrm{ml}, \mathrm{LDH}$ - $366 \mathrm{IU} / \mathrm{L}, \mathrm{CA} 125$ - $212.9 \mathrm{U} / \mathrm{ml}$, CEA - 1.32 $\mathrm{ng} / \mathrm{ml}$ and CA - $19-9-28.0 \mathrm{U} / \mathrm{ml}$.

Contrast enhanced computed tomography (CECT) chest was done on $31 / 10 / 2020$ which showed partial loss of volume of left lung with fibrocystic lesions having patchy ground glass hazy appearance suggestive of irregular traction bronchiectasis of the left upper lobe. There was septal thickening with centrilobular nodules in the rest of the left lung which were tubercular in origin with secondary reactivation.

\section{PATHOLOGICAL DISCUSSION}

Frozen section of both the ovarian masses showed features suggestive of borderline serous tumour. On gross examination, (Figure 1) right ovary, had small, multiple soft tissue fragments, measuring $6 \times 5 \times 1 \mathrm{~cm}$ whereas left ovary was partly ruptured measuring $25 \times 20 \times 9 \mathrm{~cm}$. Ascitic fluid cytology was negative for malignancy. Gram staining of fluid showed no organisms. LDH / ADA / DLC / TLC of fluid: 1070 IU / L, 30.7 U / L, 30 \%, lymphocytes - 70 \%, basophil - $00 \%$ respectively; background showed mesothelial cells and culture of fluid was found to be sterile. The clinical findings were as follows; the right ovary and left ovarian capsules were ruptured. Tumour site involved bilateral ovaries. Ovarian surface involvement was present with tumour size in right ovary as $4 \times 3.5 \times 3 \mathrm{~cm}$ and in left ovary $4.5 \times 3 \times 2.5 \mathrm{~cm}$. Histological type was found to be serous borderline tumour / atypical proliferative serous tumour, with histologic grade to be low grade (Figure 2).
Right and left fallopian tubes were not involved by tumour and were within normal histological limits. No regional lymph node involvement was seen. Omentum was also not involved by tumour but rectosigmoid was involved by the tumour.

\section{Impression}

There was bilateral ovarian mass, which could be either serous borderline tumour / atypical proliferative serous tumour. bilateral salpingo-oophorectomy was performed.
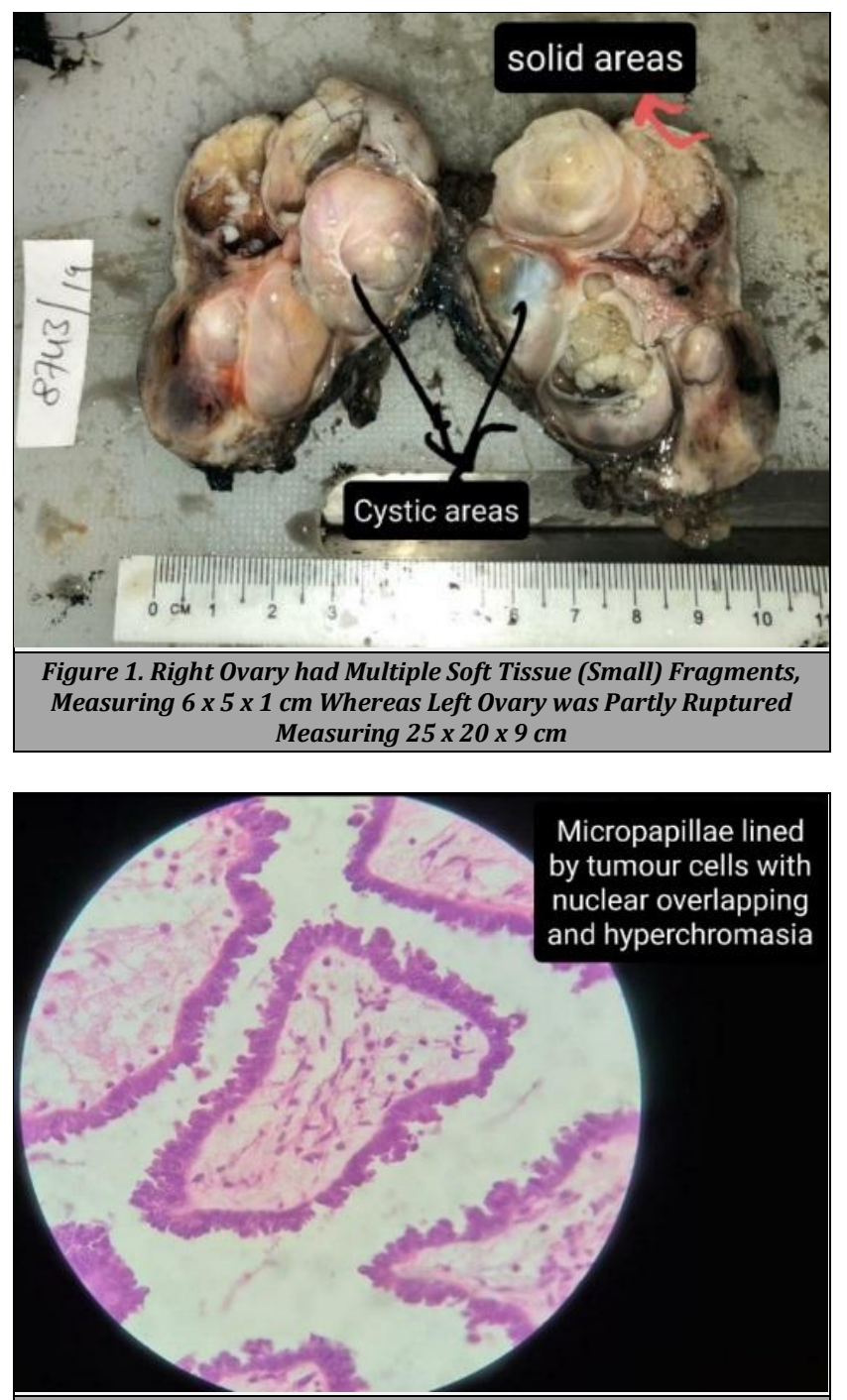

Figure 2. Serous Borderline Tumour / Atypical Proliferative Serous Tumour, with Histologic Grade to Be Low Grade

Pathological staging was pT2bNxMx. Clinical staging was 1C1. Patient was then advised for adjuvant chemotherapy with paclitaxel and carboplatin for minimum of 6 cycles, but patient did not come for follow up.

\section{DISCUSSION OF MANAGEMENT}

Patient was then planned for exploratory laparotomy in view of malignant ovarian mass. Procedure performed was exploratory staging laparotomy followed by bilateral salpingo -oophorectomy. 


\section{Intraoperatively}

Ascitic fluid: $100 \mathrm{ml}$ straw coloured fluid was sent for analysis. There was a large $20 \times 20 \mathrm{~cm}$ mass originating from left ovary which was adherent posteriorly to the gut. Mass arising from left ovary and left fallopian tube was dissected from the gut. The right ovary $(10 \times 5 \mathrm{~cm})$ had multiple fleshy papillary outgrowths (Figure 3) and was removed along with right fallopian tube. Omental biopsy was taken. A hard, yellow patch of $2 \times 1 \mathrm{~cm}$ on Pouch of Douglas was seen extending to rectosigmoid. Specimens were sent for frozen section. The uterus was normal. Frozen section showed borderline serous tumour as capsules of both the ovaries were found to be ruptured.

Rest of the staging procedure was completed and bilateral salpingo-oophorectomy was done. Postoperatively, patient had an uneventful recovery.

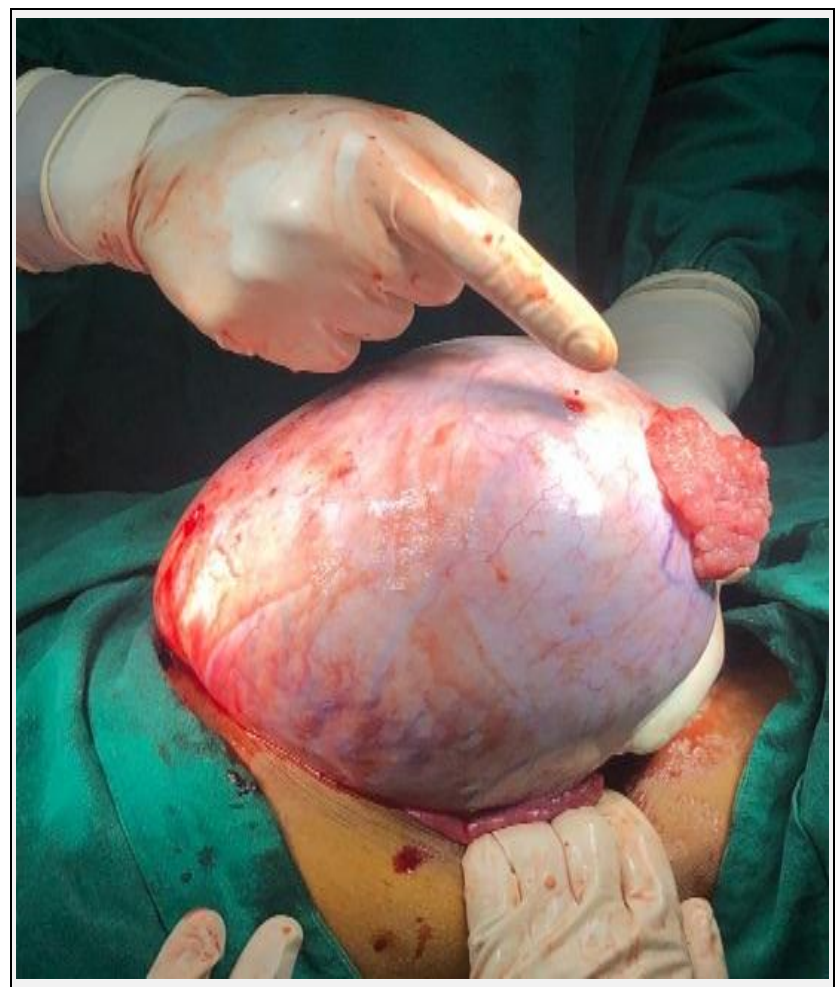

Figure 3. A Large $20 \times 20 \mathrm{~cm}$ Mass Originating from Left Ovary and Left Fallopian Tube Adherent Posteriorly to Gut. Mass Arising from Right Ovary 10 X $5 \mathrm{~cm}$ with Multiple Fleshy Papillary Excrescence

\section{DISCUSSION}

Considering the patient's overall profile, there was preoperative diagnostic dilemma as to whether the treatment should be conservative or surgical. One possibility was of abdominal Koch's and on other side there was a high possibility of malignancy. Taking all the factors into consideration we decided for surgical intervention. Management of this type of case requires combined efforts of surgeon and pathologist. An intraoperative examination helps in making the final diagnosis. It is necessary for surgeons to be aware that the diagnosis of the frozen section is based on microscopy of only a few parts of the most suspicious region of the tumour grossly found, whereas the final diagnosis is made after assessment of an internationally agreed norm of at least one section per $\mathrm{cm}$ of maximum tumour diameter. ${ }^{2}$ Surgical management of BOTs based solely on intraoperative diagnosis of the frozen section should be used with caution as accurate treatment is doubtful.

Around 10 percent of all ovarian serous tumours fall into the low malignant potential or borderline tumour group and 50 percent of them arise before 40 years of age. The following are the histopathological findings for the diagnosis of serous borderline tumours. Pseudo stratification, tufting, cribriform and micropapillary architecture of epithelial hyperplasia. Cell clusters were detached by mild nuclear atypia and mild increased mitotic activity. There was absence of dangerous stromal invasion (i.e., without tissue destruction).

Serous borderline tumours consisting of an exuberant micropapillary architecture show micropapillary characteristics; these tumours are usually bilateral, exophytic, and high-stage than the normal serous borderline tumours.

Advances in transvaginal ultrasonography have reported a very high level of (> 95 percent) sensitivity for early stage ovarian cancer detection. A valuable adjunct to ultrasonography is transvaginal colour flow Doppler to test the vascularity of the ovarian arteries, although it is not useful for screening.

CA125 is useful in screening test during chemotherapy to treat patients with epithelial ovarian cancer.

The usual presentation of these serous ovarian tumours is abdominal pain or mass in the pelvis. It is radiologically detected. These tumours are often cystic, solid or complex, with varying quantities of solid areas.3,4,5 With low-grade serous carcinomas, serous borderline tumours (SBT) have molecular and genetic alterations. In advanced stages, they may be present in association with implants in peritoneal region and might involve lymph nodes. They are sometimes known as borderline malignant potential tumours. ${ }^{6}$ These types of masses are usually considered to be malignant on preoperative imaging due to their solid appearance with thickened septa. ${ }^{3}$

On USG, due to solid areas or papillary projections, they can be considered to be solitary or a multiloculated cystic mass. $50 \%$ of cases display enhanced vascularity. 3,7 Since their heterogeneous nature mimics a malignant ovarian neoplasm, they may not be accurately defined. On T2W images, MRI shows a low signal intensity of the solid fibrous component of the tumour and can therefore be the method of choice for characterising these complex ovarian masses. ${ }^{3,8}$

In order to qualify it as a borderline ovarian tumour, the WHO 2014 classification stated that > $10 \%$ borderline histology is required in a cystadenoma or cystadenofibroma. In contrast, in $<10 \%$ of the epithelial volume, serous cystadenomas with foci qualifying as serous borderline tumours are designated as "cystadenoma / fibroma with focal epithelial proliferation".6,9,10,11 They express WT1 (Wilms' tumour suppressor gene1), PAX8 (Paired box gene 8,), Bcl - 2 (B - cell lymphoma 2), oestrogen and progesterone receptors on immunohistochemistry.6,12,13

However, the examination of the frozen portion of BOTs is not that easy, with a slightly lower sensitivity and specificity compared to benign ovarian and ovarian cancer tumours. ${ }^{14}$ Close follow-up of patients seeking conservative treatment has to be done. ${ }^{15}$ 


\section{CONCLUSIONS}

In this case there was a problem diagnosing the mass preoperatively. There was a possibility of diagnosis of abdominal Koch and malignancy. Medical, surgical and pathological management of ovarian tumours is of vital importance in the precise diagnosis and staging of the tumour in order to establish a coordinated treatment plan for patients with serous borderline tumour.

Financial or other competing interests: None.

Disclosure forms provided by the authors are available with the full text of this article at jemds.com.

\section{REFERENCES}

[1] Wolman I. Berek and Novak's Gynecology. 15 th edn. Lippincott Williams and Wilkins 2012: p. 1560.

[2] Loughrey MB. Standards and datasets for reporting cancers. London: Royal College of Pathologists 2008.

[3] Wasnik A, Elsayes K. Ovarian cystadenofibroma: a masquerader of malignancy. Indian J Radiol Imaging 2010;20(4):297-9.

[4] Cho SM, Byun JY, Rha SE, et al. CT and MRI findings of cystadenofibromas of the ovary. Eur Radiol 2004;14(5):798-804.

[5] Jung DC, Kim SH, Kim SH. MR imaging findings of ovarian cystadenofibroma and cystadenocarcinofibroma: clues for the differential diagnosis. Korean J Radiol 2006;7(3):199-204.
[6] Hauptmann S, Friedrich $\mathrm{K}$, Redline $\mathrm{R}$, et al. Ovarian borderline tumors in the 2014 WHO classification: evolving concepts and diagnostic criteria. Virchows Arch 2017;470(2):125-42.

[7] Alcázar JL, Errasti T, Mínguez JA, et al. Sonographic features of ovarian cystadenofibromas: spectrum of findings. J Ultrasound Med 2001;20(8):915-9.

[8] Moon WJ, Koh BH, Kim SK, et al. Brenner tumor of the ovary: CT and MR findings. J Comput Assist Tomogr 2000;24(1):72-6.

[9] Silverberg SG, Bell DA, Kurman RJ, et al. Borderline ovarian tumors: key points and workshop summary. Hum Pathol 2004;35(8):910-7.

[10] Kurman RJ, Carcangiu ML, Herrington CS, et al. WHO classification of tumours of female reproductive organs. Lyon: IARC 2014.

[11] Bell DA, Longacre TA, Prat J, et al. Serous borderline (low malignant potential, atypical proliferative) ovarian tumors: workshop perspectives. Hum Pathol 2004;35(8):934-48.

[12] Barcena C, Oliva E. WT1 expression in the female genital tract. Adv Anat Pathol 2011;18(6):454-65.

[13] Laury AR, Hornick JL, Perets R, et al. PAX8 reliably distinguishes ovarian serous tumors from malignant mesothelioma. Am J Surg Pathol 2010 34(5):627-35.

[14] Rose PG, Rubin RB, Nelson BE, et al. Accuracy of frozensection (intraoperative consultation) diagnosis of ovarian tumors. Am J Obstet Gynecol 1994;171(3):823-6.

[15] Lenhard MS, Mitterer S, Kümper C, et al. Long-term follow-up after ovarian borderline tumor: relapse and survival in a large patient cohort. Eur J Obstet Gynecol Reprod Biol 2009;145(2):189-94. 